\title{
Effect of 14-Membered Ring Macrolide Therapy on Chronic Respiratory Tract Infections and Polymorphonuclear Leukocyte Activity
}

\author{
Toshihiro ShIRAI, Atsuhiko Sato and Kingo ChidA
}

\begin{abstract}
We studied the efficacy of the long-term administration of 14-membered ring macrolides in treating patients with diffuse panbronchiolitis (DPB) (34 patients) and bronchiectasis (BE) (40 patients). Oral administration of erythromycin $(400 \mathrm{or} 600 \mathrm{mg})$, roxithromycin ( $150 \mathrm{or} 300 \mathrm{mg}$ ) or clarithromycin ( 200 or $400 \mathrm{mg}$ ) given daily for at least 2 months, was evaluated. The efficacy of erythromycin, roxithromycin, and clarithromycin in DPB was 19/24 (79\%), 6/7 (86\%), and 2/3 $(67 \%)$, respectively. Efficacy of these agents in BE exceeded $50 \%$. We determined the effect of these macrolides on the activity of polymorphonuclear leukocytes (PMNs) obtained from healthy volunteers. There were no significant differences between the effects of these 14-membered ring macrolides and josamycin, a 16-membered ring macrolide which was previously found to be ineffective in treating DPB. Thus, the effectiveness of the 14-membered ring macrolides in treating DPB appears to depend on mechanism(s) other than alterations in PMN activity.
\end{abstract}

(Internal Medicine 34: 469-474, 1995)

Key words: diffuse panbronchiolitis, bronchiectasis, erythromycin, roxithromycin, clarithromycin

\section{Introduction}

Diffuse panbronchiolitis (DPB) is a chronic inflammation of the respiratory bronchioles $(1,2)$; it is also termed bronchiolitis and peribronchiolitis. The condition is diagnosed radiographically by the presence of micronodular shadows that are diffusely disseminated throughout both lungs.

Although the prognosis of DPB is poor, Kudoh et al (3) reported that the long-term administration of low doses of erythromycin, a 14-membered ring macrolide, is highly effective in improving the clinical symptoms, pulmonary dysfunction, and hypoxia in this disorder (4-6). These benefits were obtained without the eradication of bacteria from the sputum such as Pseudomonas aeruginosa, which is resistant to erythromycin.

While the mechanisms that underlie the efficacy of erythromycin in treating DPB are unknown, findings suggest that they depend on other than microbicidal activity. Recent reports have indicated that polymorphonuclear leukocytes (PMNs) may be involved in the deterioration of patients with DPB by producing a persistent, excessive influx of PMNs into the lung. Such cells produce a variety of oxidants and proteolytic enzymes, which ultimately damage the lung parenchyma (7-10). Erythromycin inhibits PMN chemotaxis (11). Treatment with this antibiotic reduces the amount of PMN and PMN-derived elastolytic-like activity in bronchoalveolar lavage fluid (12). Two new relatives of erythromycin, roxithromycin and clarithromycin, also 14membered ring macrolides, achieve higher serum levels than erythromycin and have longer half-lives (13). The 16-membered ring macrolide, josamycin however, is ineffective in treating DPB (14).

We conducted this study to determine whether erythromycin and its two derivatives would produce similar benefits in patients with DPB and bronchiectasis (BE). We also tried to determine how these antibiotics, as well as josamycin, act in these diseases by conducting an in vitro study to compare PMN activities including chemotaxis, phagocytosis, and oxygen radical generation.

\section{Materials and Methods}

\section{Clinical profile of patients}

We studied 74 patients with chronic lower respiratory tract infection, including DPB and BE. The clinical background of

From the Second Division, Department of Internal Medicine, Hamamatsu University School of Medicine, Hamamatsu Received for publication June 20, 1994; Accepted for publication January 27, 1995

Reprint requests should be addressed to Dr. Toshihiro Shirai, the Second Division, Department of Internal Medicine, Hamamatsu University School of Medicine, 3600 Handa-cho, Hamamatsu 431-31 
each patient is summarized in Table 1 . Twenty patients were diagnosed as having DPB from the examination of open lung biopsy specimens. In another 14 patients with computed tomographic (CT) findings compatible with DPB, noninvasive diagnostic procedures confirmed the presence of DPB based on the criteria proposed by the Japanese Ministry of Health and Welfare (1). Forty patients had BE that had been diagnosed on the basis of CT or bronchography. All patients demonstrated the symptoms of DPB or BE, i.e., chronic cough, purulent sputum, and dyspnea on exertion (DOE). Moist or dry rales were also heard on auscultation. Each patient received one of the following macrolide antibiotics orally each day for at least two months: erythromycin (400 or $600 \mathrm{mg} /$ day), roxithromycin ( 150 or $300 \mathrm{mg} /$ day), or clarithromycin ( 200 or $400 \mathrm{mg} /$ day). Of the three groups, the DPB patients given erythromycin had the longest duration of symptoms, and their condition was judged to be more severe, based on DOE grade, results of pulmonary function tests and of $\mathrm{PaO}_{2}$ analyses. Chest X-rays of all cases of DPB showed hyperinflation, diffuse micronodular shadows, and peribronchial thickening in both lungs. Patients with BE assigned to receive roxithromycin or clarithromycin had essentially normal pulmonary function. Some patients with DPB or
BE showed colonization with such bacteria as Pseudomonas aeruginosa, Hemophilus influenzae, or Streptococcus pneumoniae. No patient had an acute exacerbation at the outset of the study.

\section{Evaluation of efficacy}

Antibiotic efficacy in DPB was determined by evaluating the clinical symptom of DOE, results of $\mathrm{FEV}_{1}$, analysis of arterial blood gases $\left(\mathrm{PaO}_{2}\right)$, and findings on chest X-ray. Treatment for DPB was judged effective if one of the following was observed: an improved DOE score according to the Hugh-Jones classification; a $20 \%$ or greater improvement in the $\mathrm{FEV}_{1}$ or in the $\mathrm{PaO}_{2}$; or the disappearance of micronodular shadows from chest X-rays. Efficacy in BE was defined as an improvement in one or more clinical symptoms or signs, including cough, sputum, and rales, or in chest X-rays.

\section{Effect on activity of polymorphonuclear leukocytes}

Peripheral venous blood was sampled from five patients before and after the long-term administration of roxithromycin. PMNs were isolated by Ficoll-Hypaque (Mono-Poly Resolving Medium, Flow Laboratories, Irvine, Scotland) density gradient

Table 1. Clinical Characteristics of Patients with Diffuse Panbronchiolitis (DPB) and Bronchiectasis (BE)

\begin{tabular}{|c|c|c|c|c|c|}
\hline & \multirow{2}{*}{$\begin{array}{c}\text { Erythromycin } \\
\text { DPB }\end{array}$} & \multicolumn{2}{|c|}{ Roxithromycin } & \multicolumn{2}{|c|}{ Clarithromycin } \\
\hline & & DPB & $\mathrm{BE}$ & DPB & $\mathrm{BE}$ \\
\hline Patients, $\mathrm{n}$ & 24 & 7 & 24 & 3 & 16 \\
\hline Age, yr* & $52 \pm 12$ & $58 \pm 19$ & $59 \pm 14$ & $64 \pm 4$ & $63 \pm 11$ \\
\hline Range & $27-77$ & $22-76$ & $38-84$ & $59-66$ & $41-83$ \\
\hline \multicolumn{6}{|l|}{ Sex } \\
\hline Male & 11 & 3 & 12 & 0 & 5 \\
\hline Female & 13 & 4 & 12 & 3 & 11 \\
\hline Duration of symptom, yr* & $11 \pm 6$ & $9 \pm 6$ & $13 \pm 12$ & $4 \pm 4$ & $4 \pm 6$ \\
\hline Range & $2-25$ & $1-16$ & $1-44$ & $1-9$ & $1-18$ \\
\hline History of chronic sinusitis, $n$ & 23 & 6 & 14 & 1 & 3 \\
\hline \multicolumn{6}{|c|}{ Grade of dyspnea on exertion, $\mathrm{n}^{* *}$} \\
\hline I & 0 & 4 & 18 & 2 & 14 \\
\hline II & 0 & 2 & 6 & 0 & 2 \\
\hline III & 3 & 1 & 0 & 1 & 0 \\
\hline IV & 18 & 0 & 0 & 0 & 0 \\
\hline V & 3 & 0 & 0 & 0 & 0 \\
\hline \multicolumn{6}{|l|}{ Pulmonary function tests* } \\
\hline$\% \mathrm{VC}, \%$ & $60.9 \pm 21.9$ & $75.6 \pm 8.5$ & $91.1 \pm 16.8$ & $73.1 \pm 14.3$ & $95.5 \pm 26.0$ \\
\hline $\mathrm{FEV}_{1}, \mathrm{~L}$ & $1.17 \pm 0.57$ & $1.27 \pm 0.49$ & $1.79 \pm 0.47$ & $1.27 \pm 0.44$ & $1.88 \pm 0.98$ \\
\hline \multicolumn{6}{|l|}{ Arterial blood gas analysis* } \\
\hline $\mathrm{PaO}_{2}$, Torr & $65.8 \pm 10.0$ & $75.4 \pm 11.8$ & $72.6 \pm 13.2$ & $78.0 \pm 22.5$ & $84.0 \pm 19.4$ \\
\hline \multicolumn{6}{|l|}{ Bacteria cultured from sputum, $n$} \\
\hline Pseudomonas aeruginosa & 12 & 0 & 2 & 0 & 1 \\
\hline Hemophilus influenzae & 4 & 0 & 1 & 1 & 0 \\
\hline Streptococcus pneumoniae & 1 & 0 & 1 & 0 & 0 \\
\hline Duration of treatment, $\mathrm{m}^{*}$ & $23 \pm 18$ & $7 \pm 1$ & $3 \pm 1$ & $3 \pm 1$ & $3 \pm 1$ \\
\hline Range & $2-67$ & $5-8$ & $2-6$ & $2-3$ & $2-4$ \\
\hline
\end{tabular}

*Mean \pm SD. **Dyspnea graded by Hugh-Jones classification. 
centrifugation. Any residual erythrocytes were lysed with 0.15 $\mathrm{M}$ ammonium chloride, $7.2 \mathrm{mM} \mathrm{K}_{2} \mathrm{CO}_{3}$, and $97 \mu \mathrm{m}$ EDTA$\mathrm{Na}_{4}$. Cells were then washed and resuspended in Hanks' balanced salt solution (HBSS) (Nissui Pharmaceutical Co., Ltd., Tokyo, Japan). On Wright staining, the differential count showed the presence of more than $98 \%$ PMNs; the dye exclusion test confirmed a viability greater than $95 \%$.

PMN chemotaxis was measured by using modified Boyden chambers with polycarbonate filters of pore size $5 \mu \mathrm{m}$ (Chemotaxicell, Kurabo, Osaka, Japan). A volume of $600 \mu \mathrm{l}$ of a chemoattractant $\left(10^{-7} \mathrm{M}, \mathrm{N}\right.$-formyl-methionyl-leucylphenylalanine (FMLP), Sigma Chemical Co., St. Louis, MO) or of HBSS was added to the lower chamber. HBSS served as the control. Next, $200 \mu \mathrm{l}$ of PMN, $1 \times 10^{7} / \mathrm{ml}$ in HBSS, was added to each upper chamber. Each chamber was then incubated for 90 minutes at $37^{\circ} \mathrm{C}$ in humidified air with $5 \% \mathrm{CO}_{2}$. After incubation, cells in the lower chamber were counted in triplicate, and the rate of chemotaxis was calculated by the following formula: Chemotaxis rate $=(\mathrm{PMN}$ directed migration $-\mathrm{PMN}$ random migration)/PMN.

Phagocytosis was assayed according to the method previously described (15). In brief, $200 \mu \mathrm{l}$ of PMN $\left(2.5 \times 10^{6} / \mathrm{ml}\right)$, was incubated with $200 \mu \mathrm{l}$ of fluorescein isothiocyanate (FITC)labelled latex microspheres (fluoresbrite carboxylate microspheres, $\varnothing=2.37 \mu \mathrm{m}$, Polyscience Inc., Warrington, PA) at a concentration of $2.5 \times 10^{7} / \mathrm{ml}$ in HBSS in the presence of 200 $\mu l$ of autologous plasma, giving a PMN/bead ratio of $1 / 10$. After incubation at $37^{\circ} \mathrm{C}$ for 60 minutes and three washings to separate the nonphagocytotic spheres, the number of phagocytotic PMNs was evaluated with a flow cytometer (EPICSPROFILE, Coulter Corp., Miami, FL). The rate of phagocytosis was obtained by dividing the number of PMNs that had phagocytized one or more spheres by the total number of PMNs.

\section{In vitro effect of macrolides on human PMNs}

Samples of peripheral venous blood were obtained from six healthy volunteers, and PMNs were isolated as previously described. Next, each macrolide, i.e. erythromycin (Sigma Chemical Co.), roxithromycin (Eisai Co., Ltd., Tokyo), clarithromycin (Dainabot Co., Ltd., Osaka), and josamycin (Wako Pure Chemical Industries, Ltd., Osaka) was dissolved in a $0.1 \mathrm{MCH}_{3} \mathrm{COONa}$ buffer, $\mathrm{pH} 5.0$, at a concentration of $10 \mathrm{mg}$ / $\mathrm{ml}$, then diluted with HBSS to give a final concentration of 100 to $0.1 \mu \mathrm{g} / \mathrm{ml}$. For the control, the $\mathrm{CH}_{3} \mathrm{COONa}$ buffer without an antibiotic was used.

PMNs were preincubated with each antibiotic for 30 minutes at $37^{\circ} \mathrm{C}$. The effect on chemotaxis and phagocytosis was examined as described above. The generation of oxygen radicals was measured by a previously described method of chemiluminescence using a cypridina luciferin analog, 2-methyl-6-phenyl3,7-dihydroimidazo[1,2-a]pyrazin-3-one (CLA) (Tokyo Kasei Kogyo Co., Ltd., Tokyo) (16). In brief, PMNs, $1 \times 10^{5} / \mathrm{ml}$, were incubated with $5 \mu \mathrm{M}$ of CLA and the given concentration of each antibiotic in $1 \mathrm{ml}$ HBSS. The reaction was triggered by adding FMLP as a stimulus at a final concentration of $10^{-7} \mathrm{M}$. The amount of oxygen radicals generated was measured ac- cording to the greatest increase in light intensity using a luminescence reader (BLR-301, Aloka Co., Ltd., Tokyo).

\section{Statistical analysis}

Results are expressed as a mean \pm SE. Analysis used the Student's t-test or ANOVA. A level of $\mathrm{p}<0.05$ was considered as statistically significant.

\section{Results}

\section{Clinical efficacy}

With antibiotic treatment, cough and sputum ceased in most of the patients with DPB, and chest $x$-ray findings improved in some cases. Table 2 shows the change in grade of DOE, pulmonary function tests, and arterial blood gas analysis before and after antibiotic treatment. All values improved significantly in patients who received erythromycin $(\mathrm{p}<0.05)$. Patients administered roxithromycin or clarithromycin showed a trend toward improvement in each parameter. The efficacy of erythromycin, roxithromycin, and clarithromycin in DPB was 19/24 (79\%), 6/7 (86\%), and 2/3 (67\%), respectively.

Table 3 shows the improvement in clinical symptoms and chest X-ray findings in the patients given roxithromycin or clarithromycin. The efficacy of roxithromycin and clarithromycin in BE was 12/24 (50\%) and 11/16 (69\%), respectively.

\section{Chemotaxis and phagocytosis before vs. after roxithromycin therapy}

The effects on PMN chemotaxis and phagocytosis in the patients with DPB or BE who were administered roxithromycin are shown in Fig. 1. While chemotaxis was significantly re-

Table 2. Effects of Long-Term Macrolide Therapy on Diffuse Panbronchiolitis

\begin{tabular}{cccc}
\hline Parameter & $\begin{array}{c}\text { Erythromycin } \\
(\mathrm{n}=24)\end{array}$ & $\begin{array}{c}\text { Roxithromycin } \\
(\mathrm{n}=7)\end{array}$ & $\begin{array}{c}\text { Clarithromycin } \\
(\mathrm{n}=3)\end{array}$ \\
\hline Grade of DOE & $2.3 \pm 0.9 *$ & $1.9 \pm 0.9$ & $1.7 \pm 1.2$ \\
(Hugh-Jones $)$ & $1.8 \pm 0.8$ & $1.3 \pm 0.8$ & $1.5 \pm 0.8$ \\
\%VC & $60.9 \pm 21.9 *$ & $75.6 \pm 8.5$ & $73.1 \pm 14.3$ \\
$(\%)$ & $73.5 \pm 13.4$ & $81.0 \pm 11.2$ & $78.0 \pm 13.9$ \\
FEV & $1.17 \pm 0.57 *$ & $1.27 \pm 0.49$ & $1.27 \pm 0.44$ \\
$(\mathrm{~L})$ & $1.49 \pm 0.83$ & $1.70 \pm 0.73$ & $1.41 \pm 0.51$ \\
PaO $_{2}$ & $65.8 \pm 10.0 *$ & $75.4 \pm 11.8$ & $78.0 \pm 22.5$ \\
$(\mathrm{Torr})$ & $73.5 \pm 13.4$ & $76.5 \pm 9.8$ & $82.2 \pm 17.1$ \\
\hline Efficacy** & $19 / 24(79 \%)$ & $6 / 7(86 \%)$ & $2 / 3(67 \%)$ \\
\hline
\end{tabular}

Each value is mean \pm SD. Upper: pretreatment value, Lower: posttreatment value. ${ }^{*} \mathrm{p}<0.05$. ${ }^{* *}$ The antibiotic was judged effective if there was improvement in one or more of the following: grade of DOE, $\mathrm{FEV}_{1}, \mathrm{PaO}_{2}$, chest $\mathrm{X}$-ray findings. DOE: dyspnea on exertion. 
Table 3. Effects of Long-term Macrolide Therapy on Bronchiectasis

\begin{tabular}{lccc}
\hline Outcome & & $\begin{array}{c}\text { Roxithromycin } \\
(\mathrm{n}=24)\end{array}$ & $\begin{array}{c}\text { Clarithromycin } \\
(\mathrm{n}=16)\end{array}$ \\
\hline Cough & Disappeared & $8 / 24(33 \%)$ & $10 / 16(63 \%)$ \\
Sputum & Disappeared & $9 / 24(38 \%)$ & $9 / 16(56 \%)$ \\
Rales & Disappeared & $5 / 17(29 \%)$ & $7 / 12(58 \%)$ \\
Chest X-ray & Improved & $7 / 24(29 \%)$ & $6 / 16(38 \%)$ \\
\hline Efficacy* & & $12 / 24(50 \%)$ & $11 / 16(69 \%)$ \\
\hline
\end{tabular}

*The antibiotic was judged effective if there was improvement in one or more of the above parameters.

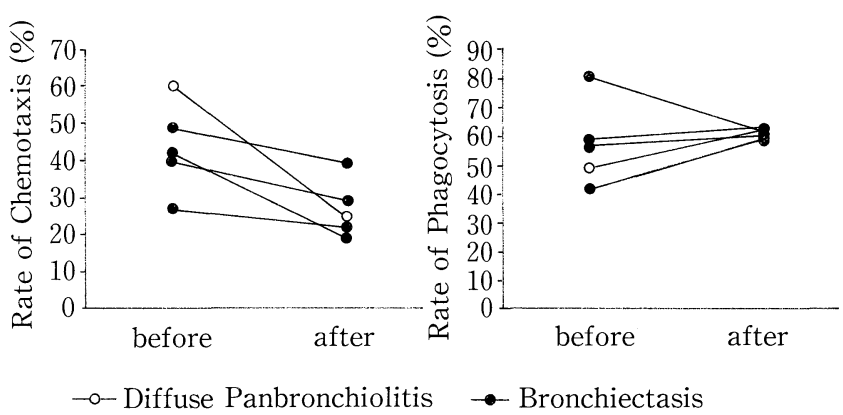

Figure 1. Chemotaxis and phagocytosis of polymorphonuclear leukocytes obtained from patients with diffuse panbronchiolitis or bronchiectasis before and after roxithromycin therapy. The rate of chemotaxis was significantly reduced from $44.0 \pm 12.1 \%$ to $27.4 \pm 7.8 \%(p<0.05$, mean \pm SE). However, the rate of phagocytosis was not significantly affected (from $57.5 \pm 14.5 \%$ to $61.4 \pm 1.6 \%)$.

duced in all five patients who had responded to roxithromycin $(p<0.05)$, overall, there were no significant changes in the rate of phagocytosis before vs. after the therapy.

\section{In vitro effect of macrolides on human PMNs}

Figure 2 illustrates the effects of each of the four macrolides on chemotaxis of PMNs obtained from six healthy volunteers. Each antibiotic given at concentrations of 1 and $10 \mu \mathrm{g} / \mathrm{ml}$, suppressed the chemotaxis induced by FMLP by approximately $10 \%$ vs. controls. A concentration of $100 \mu \mathrm{g} / \mathrm{ml}$ of roxithromycin tended to reduced the response, while that same dose of each of the other three antibiotics did not alter chemotactic activity. Differences were not statistically significant. In contrast, the phagocytosis of PMNs pretreated with a macrolide was not affected by any of the concentrations tested (Fig. 3).

The effects of each macrolide on the FMLP-activated PMNs are shown in Fig. 4. Erythromycin, clarithromycin, and josamycin each produced a dose-dependent increase in chemi-

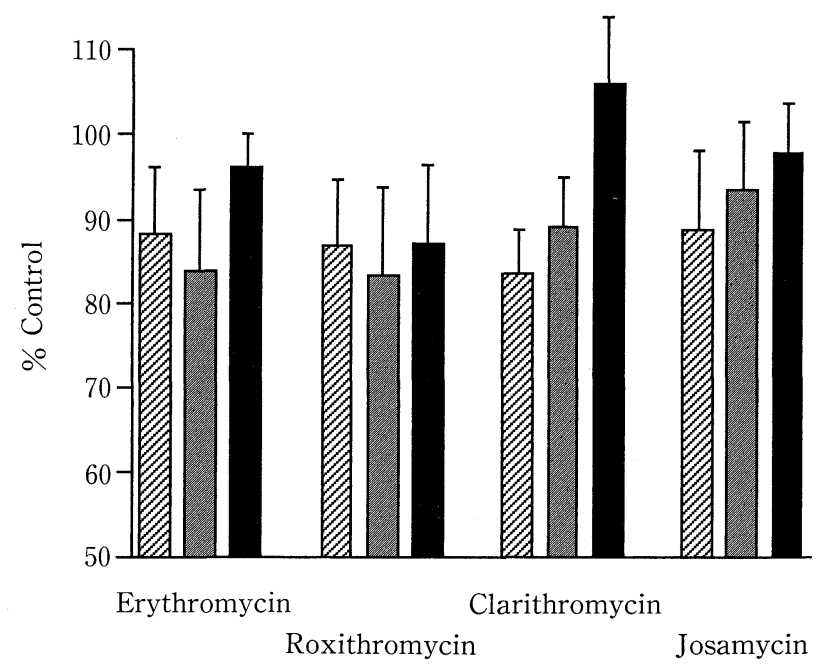

$\square_{1} \mu \mathrm{g} / \mathrm{ml} \square 10 \mu \mathrm{g} / \mathrm{ml} \square 100 \mu \mathrm{g} / \mathrm{ml}$

Figure 2. In vitro effect of macrolides on chemotaxis of polymorphonuclear leukocytes from healthy volunteers. The rate tended to be reduced by each agent (concentrations of 1 and $10 \mu \mathrm{g}$ / ml) by approximately $10 \%$. Polymorphonuclear neutrophils had been preincubated with each agent for 30 minutes at $37^{\circ} \mathrm{C}$. Data are mean $\pm S E(n=6)$.

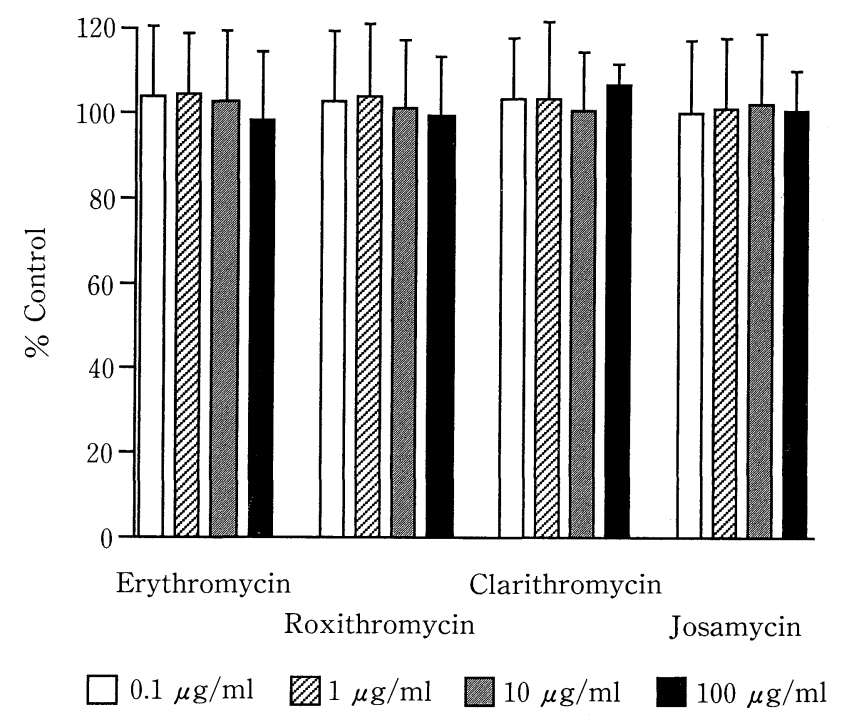

Figure 3. In vitro effect of macrolides on phagocytosis of polymorphonuclear leukocytes from healthy volunteers. None of these agents given at concentrations of from 0.1 to $100 \mu \mathrm{g} / \mathrm{ml}$ influenced the phagocytosis of polymorphonuclear leukocytes. Polymorphonuclear neutrophils had been preincubated with each agent for 30 minutes at $37^{\circ}$ C. Data are mean $\pm S E(n=4)$.

luminescence that was statistically significant at concentrations of 10 and $100 \mu \mathrm{g} / \mathrm{ml}$. At concentrations of 10 and $100 \mu \mathrm{g} / \mathrm{ml}$, the mean increases were $8 \%$ and $21 \%$ for erythromycin, $15 \%$ and $38 \%$ for clarithromycin, and $19 \%$ and $42 \%$ for josamycin, 


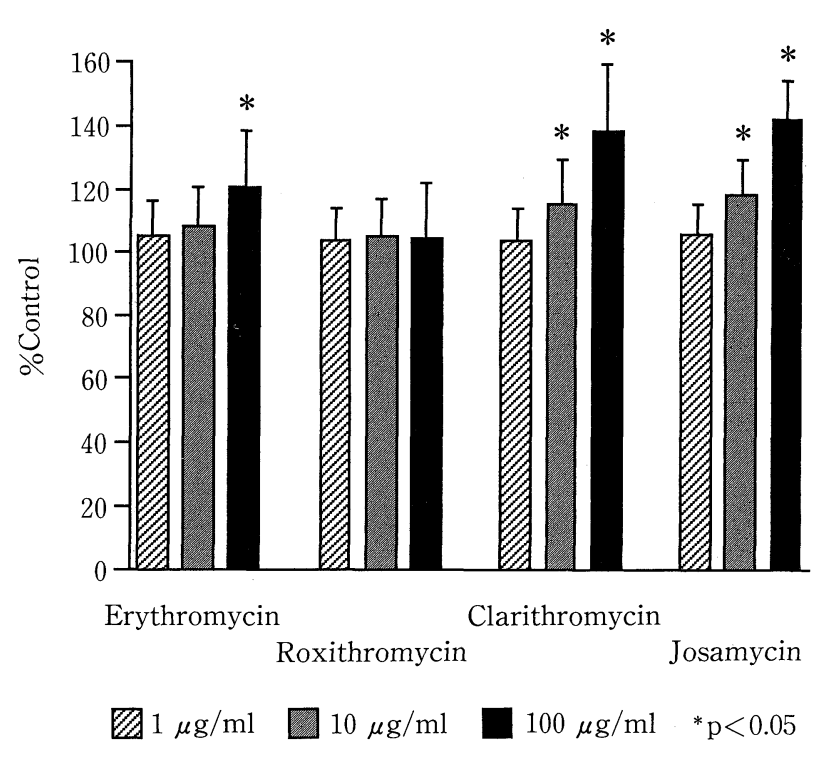

Figure 4. In vitro effect of macrolides on chemiluminescence response of polymorphonuclear leukocytes obtained from healthy volunteers. Erythromycin, clarithromycin and josamycin at concentrations of 10 and $100 \mu \mathrm{g} / \mathrm{ml}$ each significantly increased chemiluminescence $(\mathbf{p}<\mathbf{0 . 0 5})$. Roxithromycin had no effect on polymorphonuclear leukocyte chemiluminescence at any concentration. Polymorphonuclear neutrophils had been preincubated with each agent for 30 minutes at $37^{\circ} \mathrm{C}$. Data are mean $\pm \mathrm{SE}(\mathrm{n}=5)$.

respectively $(\mathrm{p}<0.05)$. However, roxithromycin at concentrations of 10 and $100 \mu \mathrm{g} / \mathrm{ml}$, and any antibiotic at a concentration of $1 \mu \mathrm{g} / \mathrm{ml}$ caused no significant change.

\section{Discussion}

To date, there is no agreement on the treatment to prevent the deterioration of a patient with chronic respiratory tract infection. While DPB has a poor prognosis, the long-term administration of a low dose of erythromycin can provide benefit (3-6). Interestingly, such a low dose of erythromycin rarely eradicates pathogens from the lower respiratory tract, unlike the conventional doses used in treating an acute exacerbation. Erythromy$c i n$ is effective even in cases with colonization of $P$ aeruginosa, which is insensitive to this antibiotic. In one study, the levels of erythromycin in the serum or sputum of a response group vs. a nonresponse group did not differ (5). These findings suggest that the efficacy of erythromycin in DPB may correlate with mechanisms unrelated to its microbicidal activity. We sought to determine whether other 14-membered macrolides would be as efficacious as erythromycin in treating patients with DPB or BE.

Results indicated that the long-term administration of roxithromycin, clarithromycin, and erythromycin were each effective in treating DPB. The long-term administration of roxithromycin and clarithromycin each improved the clinical symptoms of BE.

PMN chemotaxis was significantly reduced following roxithromycin therapy. Similar to the results previously reported with erythromycin therapy (17), the suppression of chemotaxis appeared to be related to an improvement in the patient's condition.

In the in vitro study, josamycin had the same inhibitory effect on the chemotaxis of PMNs as erythromycin, roxithromycin, and clarithromycin at the concentrations tested, even though josamycin is reportedly ineffective in treating DPB. Erythromycin, clarithromycin, and josamycin potentiated the generation of oxygen radicals by PMN, whereas roxithromycin had no effect. Thus, the ability to potentiate the generation of oxygen radicals was inconsistently observed with these 14 -membered ring macrolides.

The effects of several macrolides on chemotaxis and on the generation of oxygen radicals by PMN have been studied in vivo and in vitro, with similar results reported (18-23). Thus, it does not appear that the effectiveness of these 14-membered ring macrolides for treating DPB and BE can be explained by a direct effect on the chemotaxis, phagocytosis, and generation of oxygen radicals by PMNs. However, erythromycin exerts some effect on PMNs, as a neutrophil chemotactic factor is reportedly reduced in the bronchoalveolar lavage fluid of patients with DPB following its administration (24). Erythromycin suppresses the secretion of mucus and water from the airway membranes $(25,26)$, and inhibits activated T lymphocytes $(27)$, as well as enhances the proliferation and differentiation of the progenitors of macrophages (28).

Future studies of the immunomodulating effects of the 14membered ring macrolides should focus on the mechanism of the efficacy in treating DPB. Their effectiveness when given at low doses for treating chronic respiratory tract infection appears to not be directly related to PMN chemotaxis, phagocytosis, or the generation of oxygen radicals.

\section{References}

1) Homma $\mathrm{H}$, Yamanaka A, Tanimoto $\mathrm{S}$, et al. Diffuse panbronchiolitis: a disease of the transitional zone of the lung. Chest 83: 63, 1983.

2) Fraser RG, Paré JAP, Paré PD, Fraser RS, Genereux GP. Diffuse Panbronchiolitis. in: Diagnosis of Diseases of the Chest, 3rd ed. WB Saunders Co, Philadelphia, 1990, p. 2224.

3) Kudoh $S$, Uetake T, Hagiwara $K$, et al. Clinical effect of low-dose longterm erythromycin chemotherapy on diffuse panbronchiolitis. Jpn J Thorac Dis 25: 632, 1987 (Abstract in English).

4) Yamamoto $M$, Kondo A, Tamura M, Izumi $T$, Ina $Y$, Noda M. Long-term therapeutic effects of erythromycin and new quinolone antibacterial agents on diffuse panbronchiolitis. Jpn J Thorac Dis 28: 1305, 1990 (Abstract in English).

5) Nagai H, Shishido H, Yoneda R, Yamaguchi E, Tamura A, Kurashima A. Long-term low-dose administration of erythromycin to patients with diffuse panbronchiolitis. Respiration 58: 145, 1991.

6) Yamamoto M, Kudoh S, Noda M, et al. Efficacy of erythromycin on diffuse panbronchiolitis; randamized placebo-controlled double-blind study. Am Rev Respir Dis (manuscript in communication).

7) Ichikawa Y, Koga H, Tanaka M, Nakamura M, Tokunaga N, Kaji M. Neutrophilia in bronchoalveolar lavage fluid of diffuse panbronchiolitis. Chest 98: 917, 1990.

8) Cantin AM, North SL, Fells GA, Hubbard RC, Crystal RG. Oxidantmediated epithelial cell injury in idiopathic pulmonary fibrosis. J Clin Invest 79: 1665, 1987 


\section{SHIRAI et al}

9) Kindt GC, Weiland JE, Davis WB, Gadek JE, Dorinsky PM. Bronchiolitis in adults: a reversible cause of airway obstruction associated with airway neutrophils and neutrophil products. Am Rev Respir Dis 140: 483, 1989.

10) Amitani R, Wilson R, Rutman A, et al. Effects of human neutrophil elastase and Pseudomonas aeruginosa proteinases on human respiratory epithelium. Am J Respir Cell Mol Biol 4: 26, 1991.

11) Nelson S, Summer WR, Terry PB, Warr GA, Jakab GJ. Erythromycininduced suppression of pulmonary antibacterial defenses: a potential mechanism of superinfection in the lung. Am Rev Respir Dis 136: 1207, 1987.

12) Ichikawa $Y$, Ninomiya $H, K o g a H$, et al. Erythromycin reduces neutrophils and neutrophil-derived elastolytic-like activity in the lower respiratory tract of bronchiolitis patients. Am Rev Respir Dis 146: 196, 1992.

13) Bahal N, Nahata MC. The new macrolide antibiotics: azithromycin, clarithromycin, dirithromycin, and roxithromycin. Ann Pharmacother 26: $46,1992$.

14) Oritsu H. Efficacy of josamycin on diffuse panbronchiolitis. Therapeutic Res 11: 973, 1990 (in Japanese).

15) Steinkamp JA, Wilson JS, Saunders GC, Stewart CC. Phagocytosis: flow cytometric quantitation with fluorescent microspheres. Science 215: 64, 1982.

16) Takahashi S, Yoshikawa T, Naito Y, Tanigawa T, Yoshida N, Kondo M. Role of platelet-activating factor (PAF) in superoxide production by human polymorphonuclear leukocytes. Lipids 26: 1227, 1991.

17) Arioka $\mathrm{H}$. Effects of erythromycin on neutrophil chemotactic activity. Therapeutic Res 11: 975, 1990 (Abstract in English).

18) Eyraud A, Descotes J, Lombard JY, et al. -Effec̄ts̄ of eryth̄romycin, josamycin and spiramycin on rat polymorphonuclear leukocyte chemotaxis. Chemotherapy 32: 379, 1986.

19) Fietta A, Bersani C, Santagada T, Bertoletti R, Grassi GG. In vitro activity of macrolides on human phagocytic functions. Chemioterapia 6: 52 ,
1987.

20) Labro MT, Benna JE, Babin-Chevaye C. Comparison of the in-vitro effect of several macrolides on the oxidative burst of human neutrophils. J Antimicrob Chemother 24: 561, 1989.

21) Torre D, Broggini M, Botta V, Sampietro C, Busarello R, Garberi C. In vitro and ex vivo effects of recent and new macrolide antibiotics on chemotaxis of human polymorphonuclear leukocytes. J Chemother 3: 236, 1991.

22) Fraschini F, Scaglione F, Ferrara F, Marelli O, Braga PC, Teodori F. Evaluation of the immunostimulating activity of erythromycin in man. Chemotherapy 32: 286, 1986.

23) Roszkowski K, Beuth J, Ko HL, Peters G, Pulverer G. Comparative study on the macrolides erythromycin and clarithromycin: antibacterial activity and influence on immune responses. Zbl Bakt 273: 518, 1990.

24) Kadota J, Sakito O, Kohno S, et al. A mechanism of erythromycin treatment in patients with diffuse panbronchiolitis. Am Rev Respir Dis 147: 153, 1993.

25) Goswami SK, Kivity S, Marom Z. Erythromycin inhibits respiratory glycoconjugate secretion from human airways in vitro. Am Rev Respir Dis 141: 72, 1990.

26) Tamaoki J, Isono K, Sakai N, Kanemura T, Konno K. Erythromycin inhibits Cl secretion across canine tracheal epithelial cells. Eur Respir J 5: 234, 1992.

27) Sugiyama Y, Sugama Y, Takeuchi K, Kudoh S, Kitamura S. Analysis of peripheral lymphocyte subsets and changes due to erythromycin therapy in patients with diffuse panbronchiolitis. Jpn J Thorac Dis 28: 1574, 1990 (Abstract in English).

28) Katahira J, Hasegawa $H$, Shibata $Y$, et al. The effect of macrolides on the proliferation of hemopoietic progenitor cells. Int J Exp Clin Chemother 3: 10,1990 . 